\title{
Elektronik Danışma Hizmetleri
}

\author{
Digital Reference Services
}

\section{Nazan Uçak*}

\section{Öz}

Bu makale genel olarak elektronik danışma hizmetleri ${ }^{\star \star}$ ile ilgilidir. Elektronik danışma hizmetlerinin gelişimi, geleneksel danışma hizmetlerinden farkı, oluşumunu etkileyen nedenler, nasıl oluşturulması gerektiği, teknik ve hizmetin uygulanmasıly ilgili standartlar yazıda ele alınmıştır. Ayrıca bu alanda geliştirilen projeler, işbirliğinin önemi ve işbirliği örnekleri, uygulamada karşılaşılan sorunlar ve kütüphanecilerin konuya yaklaşımlarına da değinilmiştir.

Anahtar sözcükler: Elektronik danışma hizmetleri.

\begin{abstract}
This paper is mainly related to digital reference services. Evaluation of these services, their discrepancy from the traditional reference services, factors which cause their emergence, related technical and quantitative standards are presented. Additionaly, projects which are developed in this area, the importance of cooperation activities, application problems and how librarians approach to these issues are examined.
\end{abstract}

Keywords: Digital reference services.

\footnotetext{
*Doç.Dr.; Hacettepe Üniversitesi Edebiyat Fakültesi Bilgi ve Belge Yönetimi Bölümü Beytepe 06532-Ankara (ucak@hacettepe.edu.tr).

** Elektronik danışma hizmetleri "digital reference services” karşılı̆ı olarak kullanılmıştır.
} 


\section{Giriş}

Kütüphanelerin üç temel işlevi bilgiyi sağlama, düzenleme ve yaymadır. Bunlardan bilginin yayımı ile ilgili olan danışma hizmetleri, yaygın tanımıyla bilgi arayan kullanıcıya bireysel yardım sağlama anlamında kullanılmaktadır (Galvin, 1978, s. 210). Kütüphanenin türü ne olursa olsun danışma hizmeti kullanıcıların bilgiye erişiminde yardım isteğini karşılamaya yöneliktir. Koleksiyondaki herhangi bir kaynağın bulunmasından, karmaşık araştırma sorularının yanıtlanmasına kadar her tür sorunun yanıtlanması danışma bölümünün görevidir. Bu görevler yerine getirilirken doğruluk, tamlık, güvenilirlik" soruları zamanında yanıtlama, eğitim, erişim ve bireysellik gibi bazı temel değerler esas alınır. Bu değerlere farklı açılardan yaklaşılarak farklı danışma modelleri tasarlanmıştır. Geliştirilen modellerde bazı değerler öncelikli iken, bazıları ikinci planda kalmıştır. Bu değerlendirmede önemli olan hizmet verilen kullanıcı grubunun özellikleri ve beklentileridir (Tyckoson, 2001).

Kullanıcılara bireysel yardımın sağlanmasında önemli olan, "en kısa sürede", en uygun, doğru, isabetli ve güvenilir bilginin bireylerin gereksinimini karşılayacak şekilde sağlanıp, düzenlenerek sunulmasıdır. Danışma hizmetinin ilk oluşturulmaya başlandığı 1876 yılından bu yana, en kısa süre anlayışı ile birlikte kullanıcı beklentilerine göre bu hizmetin verilmesi kavramlarında da büyük ölçüde değişiklikler olmuştur. İşin felsefesi her ne kadar kullanıcıya yardım anlamında aynı ise de, gelişen teknoloji ve bunların bilgi hizmetlerinde hızla yaygınlaşmasına paralel olarak danışma hizmetinin yerine getirilişinde köklü değişiklikler yaşanmaktadır. Bu değişimin son yıllarda giderek hız kazandığı görülmektedir. Fritch ve Mandernack'e (2001) göre, kütüphaneciliğin tarihsel gelişimine bakıldığında geçen yüzyılın büyük bir bölümünün belli ve durağan bir çizgisi olduğu söylenebilir. Bu dönemde bilgi üretimindeki hızlı artışa rağmen bilginin üretimi, düzenlenmesi ve dağıtımı; profesyonel kurumlar, yayıncılar, kitapçılar ve kütüphaneciler tarafından büyük ölçüde kontrol altında tutulabilmiştir. Ancak özellikle son on yıllık süre içinde bu durum giderek daha kontrolsüz ve kaotik bir ortama doğru kaymaktadır. Basılı bilginin artışı bütün hızıyla devam ederken, diğer yandan internet ortamında bilginin üretilmesi, dağıtımı ve erişimi bu alandaki kontrolü zorlaştırmaktadır. Ayrıca elektronik ortamdaki bilgiye erişimde zaman ve mekan sınırlarının ortadan kalkması, bilgi hizmetlerinin geleneksel yapısını temelden 
sarsmaktadır. Bu durum, özellikle bilgi teknolojilerindeki değişimlerden hemen etkilenen danışma hizmetlerinin işlevlerini yakından etkilemektedir.

\section{Değişen Bilgi Ortamı ve Danışma Hizmeti}

Geçen yüzyılın sonlarından bu yana giderek artan bir hızla süregelen değişim, bilgi ortamlarının ve bilgi merkezlerinin gelenekselden sayısala doğru bir değişim geçirdiğini göstermektedir. Chandler (2001) bu değişimi Sutton'a (1996) dayanarak şu dört grup altında vermektedir:

1. Geleneksel dönem: Bilgi merkezlerindeki koleksiyonunun kitap, dergi gibi basılı kaynaklarla sınırlı olduğu dönem.

2. Otomasyon dönemi: Basılı ve elektronik ortamda kayıtlı bilginin bir arada yer aldığı dönem.

3. Karışık dönem: Basılı ortamın yanı sıra elektronik kaynakların da kullanıldığı ve bunlara uzaktan erişimin mümkün olduğu dönem.

4. Elektronik dönem: Elle tutulur belli bir koleksiyona sahip olmaksızın, farklı iletişim araçları ile zaman ve coğrafik sınırlamalardan bağımsız, bilgiye erişilip dağıımının yapıldığı dönem.

Pek çok kütüphane henüz son aşama düzeyinde değilse de, değişimin zorlayıcı etkisi hepsi için geçerlidir. Bu etkinin ardında kullanıcının beklentileri ve teknolojinin yaygın kullanımı yatmaktadır. Günümüzün bilgi ortamı sadece kütüphaneleri değil, toplumun tüm bireylerini etkilemekte ve beraberinde avantajlarla birlikte sorunlar da getirmektedir. Bugünün bilgi ortamının en büyük özelliği; bilgisayar ve internet kullanımının yaygınlaşması, elektronik ortamda iletişimin tüm dünyada büyük ölçüde kabul görmesi, bilgi kaynaklarının çeşitlenmesi ve elektronik ortamdaki kaynaklara erişimde internetin getirdiği kolaylıklardır. Bunlar teknolojinin bilgi ortamına sağladığı avantajlardır. Ancak bunun yanı sıra, web sitelerinin kısa ömürlü ve değişken oluşu, internetin doğru, yanlış, güvenilir, güvenilmez pek çok bilgiyi kapsamasıyla giderek daha karmaşık bir yapıya sahip olması, web üzerindeki kısa ömürlü ve değişken bilginin yeterince düzenlenememesi, bilgiye erişimde farklı arama motorları ve çok çeşitli erişim yöntemlerinin bulunması, ayrıca basılı formdaki bilgi üretim artışının da bütün hızıyla devam etmesi bugünkü bilgi ortamının özellikleri olarak karşımıza çıkmaktadır (Fritch ve Mandernack 2001, s. 290). 
Amacı kullanıcıya hizmet olan, bilgi ile kullanıcı arasında bir bağ kurma görevini üstlenen danışma hizmetlerinin bilgi ortamındaki bu değişimden etkilenmemesi düşünülemez. Üstelik bu etki çift yönlüdür. Bilgi kaynakları ve bilgi teknolojisindeki gelişmeler değişim için zorlayıcı bir güç olurken, bilgi teknolojilerinin toplumda hızla yayılması ve kullanıcı beklentilerinin buna paralel olarak artması bir diğer itici gücü oluşturmaktadır. Nitekim son on yıllık literatürde bu konunun sıkça ele alındığı ve son birkaç yılda çıkan yazılarda ise danışma hizmetinin geleceğinin (var mı-yok mu) olduğu üzerine tartışmalar yapıldığı görülmektedir (Wilson, 2000; McGlamery ve Coffman 2000; Fritch ve Mandernack 2001).

Danışma kütüphanecisinin kullanıcının bilgi gereksinimini karşılamadaki tarihsel rolünün, yıllar geçtikçe bu ihtiyacın karşılanmasında kullanılan tekniklere ve yöntemlere bağlı olarak değiştiğini vurgulayan Chandler (2001), değişimin nedenlerini Mardikian ve Kesselman'a (1995) dayanarak şu beş başlık altında özetlemektedir:

1. Kütüphane dışından erişilen kaynakların artışı,

2. Kullanıcılar için coğrafik sınırlamaların ortadan kalkması, kütüphaneye gelme zorunluluğunun olmaması,

3. Farklı kullanıcılar için farklı hizmet tasarlama gereği ve buna bağlı bütçe sorunları,

4. Bilgi kaynaklarının çeşitlenmesi ve bireye özel bilgi ihtiyacı,

5. Danışma sorularının yanıtlanmasında yeni seçeneklerin ortaya çıkması.

Danışma hizmetlerindeki değişim özellikle 1980 sonrası hız kazanmıştır. Çevrim içi yayın tarama hizmetleri, CD-ROM'ların kullanımı, bilgi ağları, elektronik kaynaklara aracısız erişim olanağı, lisans anlaşmaları ve konsorsiyumlar hizmetin tasarımında etkili olan gelişmelerdir. 1990 sonrası internet ve web ortamının kullanımıyla birlikte yüz yüze danışma hizmetinin yerini elektronik posta ve web üzerindeki formların doldurulması ile yürütülen danışma hizmetleri almaya başlamıştır. Gorman'a (2001) göre 125 yıldır devam eden kullanıcıların sorularının dinlenerek yanıt arandığı yüz yüze görüşmeler giderek popülerliğini yitirmektedir. Ancak yüz yüze görüşmenin sağladığı avantajları internet ortamında verilen danışma hizmetinin ne derece sağlayabildiği de tartışılmalıdır. 


\section{Elektronik Danışma Hizmeti}

Elektronik danışma hizmeti; genel olarak, geleneksel danışma hizmetinin sayısal ortamda yeni boyutları ile yeniden tanımlanmasıdır (Lankes, 2000). Bir başka tanıma göre, "A'ya Sor" (Ask $A$ ) olarak da bilinen elektronik danışma hizmeti kullanıcıların, kütüphaneciler ve konu uzmanları ile internet üzerinden iletişim kurarak sorularına yanıt alabildikleri bir hizmettir (Virtual Reference Desk, 2003). Elektronik danışma terminolojisinin henüz çok yeni olması bu alanda bazı terimlerin kullanımında karışıklığa neden olmaktadır. Özellikle elektronik danışma hizmeti (digital reference service) ile sanal danışma hizmeti (virtual reference desk) terimleri sık sık birbirinin yerine kullanılabilmektedir. Sanal danışma hizmetini elektronik danışma hizmetinden ayırarak tanımlayan Lipow (2003), sanal danışma hizmetinde eş zamanlı olarak iletişim kurmanın bu ayrımdaki temel fark olduğunu vurgulamaktadır. Sanal danışma kütüphanecisi, kullanıcısının isteklerini uzaktan, "chat" veya sesli ve görüntülü uygulamalarla ancak anında iletişim kurarak karşılamak durumundadır. Oysa ki, elektronik danışma hizmetlerinde elektronik posta ve web üzerindeki başvuru formlarının doldurulması ile yürütülen hizmetlerde gelen istek ve soruların yanıtlanması belli bir süreyi alabilmektedir. Genelde elektronik danışma hizmeti terimi elektronik danışma kaynaklarının oluşturulmasından, yönetimine; elektronik posta ve "chat" aracılığı ile kullanıcı sorularının yanıtlanmasından, internet üzerinden kullanıcıya bireysel destek sağlamaya varan bir yelpazede kullanılmaktadır. The National Information Standards Organization (NISO) bu hizmeti, elektronik danışma hizmeti için bir standart geliştirmeden önce tanımlamıştır. Buna göre elektronik danışma hizmeti, elektronik posta ve/veya "chat" aracılığı ile kullanıcı sorularının gerçek zamanlı olarak yanıtlandığı elektronik ortamdır (Lipow, 2003).

\section{Elektronik Danışma Hizmetinin Gelişimi ve İşbirliği}

Kütüphanelerde elektronik danışma hizmetleri, internetle birlikte 1990'lı yılların ortalarında başlamıştır. Yapılan iş önceleri sadece kullanıcıların elektronik posta ile yönelttikleri sorulara yanıt verilmesinden ibaretti. Daha sonra web üzerinden form doldurarak ve/veya "chat" aracılığıyla kütüphaneci ile iletişim kurarak hizmet kapsamı genişletilmiştir. Gelişen teknoloji ve kullanıcı gerek- 
sinimlerinin karşılanması için üretilen yeni yazılımlar bu hizmetin gelişiminde etkili olmuştur. Bir ticari kurum tarafından geliştirilen Library Systems and Services (LSSI) ve ABD hükümetinin desteklediği Metropolitan Cooperative Library System ile Kaliforniya Üniversitesi Kütüphanesi tarafından ortak proje olarak geliştirilen 24/7 Reference, 1990'ların sonlarında özellikle kütüphaneler için tasarlanmış çözümlerdir (Penka, 2003).

Danışma kaynaklarının ve hizmetlerinin maliyetindeki artış pek çok kütüphaneyi elektronik danışma hizmetlerinin verilmesinde işbirliğine zorlamaktadır. Bu tür işbirliği, kullanıcının bilgi gereksiniminin karşılanmasında kütüphanelerin uzmanlık alanlarına göre soruların yönlendirilebilmesine ve buna bağı olarak daha isabetli yanıtlar verilmesine olanak tanımaktadır. Ayrıca zaman, kaynak ve emek açısından tasarruf sağlanmakta, maliyet düşerken hizmet kalitesi artırımaktadır. Bu ortak projelere en önemli örnek, Kongre Kütüphanesi (Library of Congress-LC) tarafından organize edilen Collaborative Digital Reference Service² (CDRS)'dir. 1998 yılında uygulanmaya başlanan projede, üye kütüphanelerden gelen kullanıcılara ait sorular sistem içinde yer alan bilgi tabanından (knowledge base) yararlanılarak yanıtlanmaktadır. Burada uygun yanıt bulunamazsa, soru koleksiyon ve uzmanlık alanlarına göre ilgili olabilecek kütüphanelere yöneltilmektedir. Alınan yanıt, ihtiyaç sahibi kullanıcının kütüphanesine iletilmektedir. Ayrıca sorular ve verilen yanıtlar bilgi tabanında depolanarak daha sonra gelebilecek benzer soruların yanıtlanmasında kullanılmaktadır. CDRS farklı kıtalardan 260'ın üzerinde kütüphanenin katılımıyla oluşan ortak bir projedir.

LC ve OCLC'nin ortak projesi olarak 2002 yılında geliştirilen Question Point ${ }^{3}$ ise, CDRS projesinin bir sonraki aşamasını oluşturmaktadır; dünyanın pek çok yerinden zaman sınırlaması olmadan kütüphanecilerin sorularını yöneltebildiği ve uzmanlarca soruların yanıtlandığı bir ağdır (Penka, 2003).

Elektronik danışma hizmetinin gelişiminde önemli bir ortaklık projesi de The Virtual Reference Desk ${ }^{4}$ (VRD)'dir. VRD, kullanıcılar ile konu uzmanları

\footnotetext{
2 Library of Congress. Global Reference Net Work. [Çevrim içi], Elektronik adres: http://www.loc.gov/rr/digiref/

3 Question Point. [Çevrim içi], Elektronik adres: http://QuestionPoint.org/

4 The Virtual Reference Desk. [Çevrim içi], Elektronik adres:http://www.vrd.org/
} 
arasında internet ortamında soruların yanıtlanması esasına dayalı bir danışma hizmeti projesidir. Amacı ilk ve ortaöğretim öğrencilerinin (K-12 grubu), öğretmenlerin ve ebeveynlerin bilgi intiyacını karşılamaktır. Kullanıcının sorusu bağlı olduğu bilgi merkezinde karşılanamazsa VRD'e gönderilmektedir. VRD'de "A'ya Sor" (Ask A) hizmetinin yanı sıra, soru arşivi ve sık sorulan sorular bölümlerinden de yararlanılmaktadır.

Ayrıca İngiltere'deki halk kütüphaneleri için tasarlanmış olan Ask $A$ Librarian $^{5}$, Washington Üniversitesinin web için tasarladığı otomatik danışma kütüphanecileri Automatic Reference Librarians for the World Wide Web ${ }^{6}$ ve Indiana Üniversitesinin tasarladığı SIFTER ${ }^{7}$ elektronik danışma hizmetinin gelişiminde önemli projelerdir.

Bugün kütüphaneler dışında oluşturulan pek çok web tabanlı bilgi hizmeti vardır. Temelde bir arama motoru olmasına rağmen, pek çok araştırmacı tarafından bir bilgi hizmeti olarak tanınmakta ve kullanılmakta olan Ask Jeeves $^{8}$, günün her saati gerçek zamanlı tarama yardımı sağlayan Webhelp.com ${ }^{9}$, tanımlanmış kategoriler üzerinden tarama yapma olanağı sağlayan About.com ${ }^{10}$ bunlara örnek gösterilebilir. Ayrıca pek çok ticari ve yayıncı firma ürünlerini destekler nitelikte benzer danışma ve bilgi hizmeti vermektedir.

\section{Elektronik Danışma Hizmetlerinin Oluşturulması}

Elektronik danışma hizmeti oluşturmadan önce, bunun kim için ve neden gerekli olduğu üzerinde durmakta yarar vardır. Tyckoson'a göre (2001) bir kütüphane için iyi işleyen yararlı bir hizmet modeli, farklı kullanıcı grubuna hitap eden bir başka kütüphane türü için gereksiz olabilir. Bunun yanı sıra bir

\footnotetext{
5 Ask A Librarian. [Çevrim içi], Elektronik adres: http://www.earl.org.uk/ask/

6 Automatic Reference Librarians for the World Wide Web. [Çevrim içi], Elektronik adres: www.fastlane.nsf.gov/servlet/showaward?award=98747559

7 SIFTER. [Çevrim içi], Elektronik adres: http://sifter.indiana.edu

8 Ask Jeeves. [Çevrim içi], Elektronik adres: http://www.AskJeeves.com.uk

9 Webhelp. [Çevrim içi], Elektronik adres: http://www.webhelp.com

10 About.com. [Çevrim içi], Elektronik adres: http://www.about.com
} 
kütüphanenin, elektronik danışma hizmetlerini oluşturmadan önce koşullarını, yazılım ve donanım olanaklarını değerlendirmesinde yarar vardır. Lynch (2000) elektronik danışma hizmeti kurma aşamasında şu dört noktanın dikkate alınması gerektiğini belirtmektedir:

1. Öncelikle bu iş için gerekli standartlar, işlemler, işlerin tanımlanması ve gerekli personelin sağlanması gibi özellikler dikkate alınarak bir düzenleme yapılması,

2. Ikinci aşamada, mümkünse önce bir kontrol grubu ile çalışmanın sınanması, hizmetin zayıf ve kuvvetli yönleri görüldükten sonra kademeli olarak yaygınlaştırılması,

3. Ikinci basamaktaki çalışmalarla ilintili olarak yapılabileceklere karar verilmesi, hizmet kapsamının ve çalışan sayısının artırıması,

4. Son aşamada, hizmetlerin gerçekçi tanıtımıyla ilgili çalışmaların yapılmasıdır.

Geleneksel veya elektronik ortamdaki danışma hizmetinin ana amacı kullanıcıya yardımdır. Bu nedenle kullanıcının bilgiye kısa sürede ve isabetli erişebilmesi, kullanıcının hizmetler ve kaynaklar hakkında bilgilendirilmesi gibi temel özellikler her iki tür hizmet için de geçerlidir. Bu yardımın sağlanmasında araç ve ortamların değişimine paralel olarak yeni uygulamalar ve ölçütler gerekebilmektedir. Bu amaçla farklı kurumlar tarafından bazı standartlar ve kılavuzlar geliştirilmiştir. Herhangi bir kütüphanede bir elektronik danışma hizmetinin nasıl oluşturacağını anlayabilmek için, bu alanda geliştirilen kılavuz ve standartların bilinmesinde yarar vardır. Ayrıca elektronik danışma hizmeti, yapısı gereği bu hizmetin kalitesini değerlendirmede bir takım yeni ölçütlerin oluşturulmasını zorunlu kılmıştır.

\section{Elektronik Danışma Hizmetleri İle İlgili Standartlar ve Kılavuzlar}

Tüm hizmetlerde olduğu gibi danışma hizmetlerinin yürütülmesiyle ilgili kurallar ve standartlar da vardır. Kütüphaneci kullanıcı iletişimi, danışma hizmetlerinin düzenlenmesi ve işbirliği gibi konularda geliştirilen standartlar, kütüphanelerin kendi çalışma politikalarını ve ilkelerini oluşturabilmeleri açısından önemlidir. Bu standartlardaki pek çok unsur elektronik ortamda ve uzaktan verilen danışma hizmetlerine uyarlanabilir. Ancak hizmet seçenekleri çoğal- 
dıkça içine düşülen karışıklık ve var olan standartların bu hizmetlere uyumu zorlaşmaktadır. Tüm dünyada danışma hizmetlerinin internet üzerinden verilmesinde bir artış vardır. E-posta yoluyla başlayan hizmetler giderek "chat" ve video danışma hizmetlerine kadar uzanan daha kapsamlı ve karmaşık bir yapı gerektirecek şekilde genişlemektedir. Bu durum kullanıcı ile kütüphaneci arasında çevrim içi ve etkileşimli olarak iletişimi sağlayacak yazılımları gerektirmektedir. Başlangıçta hazırlanan basit yazılımlar giderek kullanıcı ile kütüphanecinin eş zamanlı tarayıcıları (synchronize browser) kullanarak, birinin ulaştığı bir web sayfasını diğerinin de görmesini sağlayan ve bu yolla kütüphanecinin kullanıcısını tarama ve bilgi kaynaklarını kullanma konusunda elektronik ortamda eğitebilmesine fırsat veren bir yapıya ulaşmıştır. 1990'larda hazırlanan standartlardan bu yana bilgi ortamı büyük ölçüde değişmiştir. Çevrim içi olarak verilen danışma hizmeti yüz yüze verilen hizmetten çok daha karmaşıktır (Ellis ve Francoeur, 2001). Bu nedenle elektronik danışma hizmetlerinin düzenlenmesinde yeni standartlara intiyaç vardır. Nitekim bazı kurumlar ve kütüphaneler tarafından elektronik danışma hizmetlerinin nasıl düzenlenip yürütülmesi gerektiği konusunda çalışmalar yapılmış ve sonucunda bazı kılavuz ve standartlar oluşturulmuştur. Bunlardan belli başlılarına değinmekte yarar vardır.

Amerikan Kütüphaneciler Derneği (ALA)'nın bir alt grubu olan "Danışma ve Kullanıcı Hizmetleri Derneği”nin (The Reference and User Service Association) danışma hizmetleri ile ilgili geliştirdiği pek çok rehber niteliğinde çalışma vardır. Bu Derneğe bağlı olarak "Makina Destekli Danışma Grubu" (Machine-Assisted Reference Section-MARS) ${ }^{11}$ elektronik danışma hizmetleriyle ilgili olarak bir kılavuz geliştirmiştir.

Elektronik danışma hizmetleri için geliştirilen standartların hem teknik (donanım-yazılım) hem de hizmetin niteliği açısından dikkate alınması gerekmektedir. Nitekim 2002 Ocak ayında NISO12 bilgi hizmetlerinde kullanılmak üzere yeni standartlar geliştirmeye başlamıştır. Lipow'a (2003) göre bu çalışmalar elektronik danışma hizmetlerinde soru-yanıt işlemlerini ve bilgi değişimini kolaylaştıracak niteliktedir.

\footnotetext{
11 Machine-Assisted Reference Section. [Çevrim içi], Elektronik adres: http://www.ala.org/rusa/mars/digrecom.html

12 The National Information Standards Organization. [Çevrim içi], Elektronik adres: http://www.niso.org/committee-az.html
} 
İşin teknik boyutu ile ilgili çalışmalar bu şekilde gelişirken elektronik danışma hizmetinin veriliş şekli ve kapsamıyla ilgili çalışmalar da yürütülmektedir. İlk kez 1997 yılında, var olan "A'ya Sor" (Ask A) servislerini ve elektronik danışma hizmetlerinin kalite ölçütlerini değerlendirmek amacıyla konunun uzmanları ve danışma kütüphanecileri bir araya gelerek tartışmışlardır. Elektronik ortamda altı ay süren tartışmalar sonucunda elektronik danışma hizmetleri için nitelik ölçütü saptanarak açıklanmıştır. Gerçi bu ölçütlerin hazırlanmasında özellikle eğitim amaçlı hizmetler (K-12 grubu) başlangıç noktasını oluşturmaktaysa da, bunların tüm elektronik danışma hizmetlerinin değerlendirilmesinde kullanılabilecek kapsamda olduğu anlaşılmaktadır. Bu ölçütler işbirliği esasına dayalı olarak hizmet veren oluşumlar tarafından da benimsenmiş ve üyeleri için uyulması gerekli ilkeler olarak uygulamaya girmiştir. Bu ilkeler; a) kullanıcı ile ilgili uygulamalar; b) hizmetin yönetimi ile ilgili uygulamalar olmak üzere iki temel başlık altında değerlendirilebilir. Soruların yanıtlanma süresi, yanıtların anlaşılır ve net olması, hizmetin etkileşimli ve öğretilebilir olması gibi unsurlar kullanıcı ile ilgili işlerin kapsamına girmektedir. Güvenilirlik, uzmanlaşma, gizlilik, ilgililik, tanıtım gibi nitelikli ve kullanıcı tatminini esas alan hizmetlerin tasarlanması ise hizmet yönetimiyle ilgili ölçütleri oluşturmaktadır (Bennett, Kasowitz ve Lankes, 2000, s. 72-73).

Bu ilkeleri kısaca açıklamakta yarar vardır.

\section{A- Kullanıc ile ilgili ilkeler}

1. Erişilebilirlik: Elektronik danışma hizmeti kolay erişilebilir olmalıdır. Kullanıcıların hizmete erişimi için elektronik posta ve web tabanlı soru formları hazırlanmalıdır.

2. Kısa sürede yanıtlama: Kullanıcı soruları mümkün olduğunca kısa sürede yanıtlanmalıdır. Kullanıcıya geri dönüş genelde hizmet politikasına ve ilgili bilgi kaynaklarına erişim süresine bağlıdır. Kullanıcı sorularının 2-5 gün içinde yanıtlanması, eğer yanıtlanamıyorsa bu durumun belirlenen sürede kullanıcıya bildirilmesi gerekir. Ideal süre, soruların 2 gün içinde cevaplanabilmesidir.

3. Açıklık: Kullanıcıya bu hizmetten ne amaçla ve nasıl yararlanacağı açık bir şekilde anlatılmalı; soru tipleri, ne kadar sürede yanıtlanacağı, mesaj ve web ortamından nasıl başvurulacağı açık ve net olarak belirtilmelidir. Bu durum kullanıcının hizmetle ilgili olarak zihninde oluşabilecek herhangi bir karışıklığı azaltırken uygun olmayan soruların sorulmasını da önleyecektir. 
4. Etkileşim: Elektronik danışma hizmetleri kullanıcı ile kütüphaneci arasında etkileşimli (interactive) bir danışma görüşmesine fırsat tanımalı, kullanıcılar sorularını konu uzmanlarına iletebilmeli, kütüphaneci sorulara açıklık kazandırabilmelidir. Kullanıcıya ait bireysel bilgiler saklı kalmak üzere, gelen soruların konu dağılımları ve düzeyleri gibi bilgiler web ortamında sunulabilmelidir.

5. Eğitim: Elektronik danışma hizmetinde uygun kaynakların bulunmasında izlenen yollar ve erişim noktaları tanıtılarak kullanıcının benzer konulardaki bilgi intiyacını kendi kendine bulabilmesi sağlanmalıdır. Böylece konu uzmanlarının bu alandaki birikiminden kullanıcı da yararlandırımalıdır.

\section{B- Hizmet gelişimi ve yönetimi ile ilgili ilkeler}

6. Güvenilirlik: Elektronik danışma hizmetinde çalışan personelin hizmet verilen konuda eğitimli ve bilgili olması gerekir. En azından bir uzmanın, kullanıcıya göndermeden önce doğruluk ve güvenilirlik açısından yanıtları gözden geçirmesi sağlanmalıdır. Özellikle "A'ya Sor" (Ask A) hizmetlerinde konuya hakim kişilerin istihdam edilmesi önemlidir. Kullanıcılar web ve elektronik posta aracılığı ile sunulan hizmetin yetkinliği ve güvenilirliği konusunda bilgilendirilmelidir. Bir ağ üzerinden işbirliğiyle verilen hizmetlerde katılımcı kurumların sorularını yanıtlayacak kişilerin uzmanlıklarını belgelemeleri gerekir.

7. Personelin yetiştirilmesi: Elektronik danışma hizmetinde görev alacak personelin eğitimi hizmetin yürütülmesi açısından önemli bir konudur. Personelin hizmet politikası, kullanıcıyla iletişim ve uygulamalar hakkında bilgilendirilmesi, eğitimdeki uygulamaların yazılı doküman haline getirilmesi ve personelin performansının değerlendirilmesi gereklidir.

8. Gizlilik: Kullanıcıya ait kişisel bilgilerin gizli tutulması temel ilkelerden biridir. Kullanıcının adı, elektronik posta adresi ve sorusu izni olmadan erişime açılamaz. Gizlilik özellikle web tabanlı sorgu formlarının arşivlenmesinde dikkate alınmalı, bireylere ait bilgiler arşivlenmeden önce form üzerinden kaldırılmalıdır.

9. Gözden geçirme: Elektronik danışma hizmetlerinin sürekli olarak gözden geçirilmesi ve değerlendirilmesi gereklidir. Bu yolla hizmetin etkinliği, güvenilirliği ve niteliği korunmuş olur. Soruların yanıtları kullanıcıya gönderil- 
meden önce veya düzenli aralıklarla izlenerek değerlendirilmeli, diğer kullanıcıların bu sorulara ve yanıtlarına web üzerinden erişebilmeleri sağlanmalıdır. Iş̧lemlerin (veya sürecin) uygulanıp uygulanmadığı ve uygulamanın hizmet politikasına uygun olup olmadığı kontrol edilmelidir.

10. İlgili bilgiye erişim sağlama: Kullanıcı sorularının yanıtlanmasının yanı sıra, kullanıcılar konularıyla ilgili bilgi kaynaklarına yönlendirebilmeli ve bilgiye erişim olanakları sağlanmalıdır. Danışmaya gelen sorular ve yanıtları konularına göre arşivlenmeli, diğer kullanıcılara da bu bilgilere erişim olanağı verilmelidir. Ayrıca internet bağlantıları aracılığı ile farklı bilgi kaynaklarına erişim fırsatları yaratılmalıdır. Kütüphanenin seçim politikası web sayfası üzerinde yer almalı; kullanıcıların sorularını yanıtlamada kullanılan kaynaklar sık sık gözden geçirilerek güncellenmelidir.

11. Tanıtım: İyi düzenlenmiş bir halkla ilişkiler planı ile hizmetlerin tanıtımı yapılmalıdır. Hizmetin tanıtımı web sitesi üzerinden yapılabileceği gibi, tartışma listelerine, potansiyel kullanıcıların adreslerine doğrudan mesaj göndererek de yapılabilir. IIlgili web sitelerinden hizmete bağlantı sağlanmalı, basılı ortamda, konferans ve toplantılarda hizmet tanıtımına yer verilmelidir (Bennett, Kasowitz ve Lankes, 2000, s. 72-77).

Elektronik danışma hizmetlerinin düzenlenmesinde diğer önemli bir çalışma IFLA'nın bir alt çalışma grubu olan "Danışma Grubu” (Reference Work Section) tarafından hazırlanmıştır. Illk kez 2001 yılı IFLA toplantısında elektronik danışma hizmetleriyle ilgili politika ve hizmet süreçlerini tanımlayan proje öneri olarak sunulmuş, daha sonra bu proje geliştirilerek elektronik danışma sürecindeki işlemler ve yapılması gerekenler ayrıntısıyla tanımlanmıştır. "IFLA Elektronik Danışma Standartları Projesi" (IFLA Digital Reference Standards Project) ${ }^{13}$ nin amacı dünyanın farklı bölgelerinde farklı uygulamaları belli standartlar altında toplayacak bir kılavuz oluşturabilmektir. IFLA'nın hazırladığı bu kılavuzda uyulması gereken ilkeler, yönetim ve uygulama olmak üzere iki temel başlık altında toplanmıştır. Bu ilkeler şu şekilde özetlenebilir:

13 IFLA Digital Reference Standards Project. [Çevrim içi], Elektronik adres: http://www.ifla.org/VII/ ayr.bkz. : http://www.ala.org/work/standards.html 


\section{I- Yönetim}

1. Danışma politikası: Amaçların tanımlanması, sorumlulukların paylaştırılması, uyulması gereken yasal düzenlemelerin belirlenmesi, hizmetin kimler tarafından kullanılacağının ve sınırlarının saptanması, ne tip soruların yanıtlanacağı, hangi konuların hizmet kapsamı dışında kalacağı, yanlış ve kötü kullanıma karşı alınacak önlemlerin belirlenmesi;

2. Maliyet: Kurumun maddi olanaklarının ve önceliklerinin saptanması, ön eylem planının hazırlanması, somut hedeflerin ve bunlara ne zaman nasıl ulaşılacağının belirlenmesi, konuyla ilgili yazılım ve hizmetlerin değerlendirilmesi, işbirliğine gidilecek kurumların saptanması;

3. Personel: Personelin niteliklerinin dikkate alınarak seçilmesi, sorumlulukların belirlenmesi, ne kadar kütüphaneci ve teknik elemana intiyaç olduğunun saptanması, personelin çalışma programının ve saatlerinin ayarlanması, hizmetin diğer işlerle bütünleştirilmesi;

4. Eğitim: Personelin kim tarafından hangi konularda nasıl yetiştirileceği, eğitimin güncelleştirilmesi, yeniliklerin takibi;

5. Arayüz tasarımı: Arayüzün nasıl tasarlanacağı, hizmetin etkinliği için gerekli yazılım ve donanımın sağlanması, bağlantıların kurulması, web sayfası özellikleri;

6. Yasal konular: Konuyla ilgili yasalar ve telif hakları, özel hayata saygı ve gizlilik, lisans anlaşmaları, konsorsiyumlarla ilişkiler;

7. Tanıtım: Hizmetin duyurulması ve tanıtılması;

8. Değerlendirme: Personel ve kullanıcı sorunlarının dikkate alınması, teknik uygulamalar ve hizmet etkinliklerinin değerlendirilmesi, istatistiklerin analizi, kütüphaneci ve kullanıcılardan alınan geri bildirimlerin hizmete yansıtılması;

9. İşbirliği: İşbirliğinin kimlerle ve nasıl kurulacağı, ortak prosedür oluşturma, kaynak paylaşımıyla ilgili sorunların çözümlenmesi konusundaki öneriler bu gruba girmektedir. 


\section{II- Uygulama}

1. Genel kılavuz: Elektronik danışma hizmetinin sunumunda yerine getirilmesi gereken genel ilkeler;

2. Içerik kuralları (eş zamanlı olmayan hizmetler için): Kullanıcıların hizmet hakkında bilgilendirilmesi, yanıtların düzenlenmesi ve sunumu, kullanılan dil, atıfların veriliş şekli, bilgi kaynaklarının seçimi ve güvenilirliği, kütüphanecinin kimliğinin bildirilmesi ve yansızlığının sağlanması;

3. Genel "chat" hizmeti: Kullanıcının "chat" kuyruğunda bekletilmemesi, soruların sırayla yanıtlanması, sık kullanılan URL'lerin listelenmesi, kütüphanecinin kimliğinin belirtilmesi, "chat" süresinin ayarlanması;

4. "Chat" oturumu: Kullanıcının bilgi gereksiniminin belirlenmesi, sorgunun daraltıması, araştırma işleminin kullanıcıya açıklanması, atıfların düzenlenmesi, iletişim kuralları, kullanılan dilin açık ve anlaşılır olması, kötü kullanıma karşı alınacak önlemler gibi kurallar da bu bölüm içinde toplanmıştır.

\section{Elektronik Danışma Hizmetinde Sorunlar ve Danışma Kütüphanecilerinin Yaklaşımı}

Lankes'e (2000) göre elektronik danışma hizmetlerinin bugün temel sorunu, kullanıcının bilgi intiyacı ile bu bilgi intiyacının karşılanmasında internet ortamında temel danışma hizmetlerinin nasıl kurulup organize edileceğidir. Danışma hizmeti geleneksel kütüphane hizmetlerinin ayrılmaz bir parçası olmasına rağmen elektronik danışma hizmetinin elektronik kütüphane kavramı içinde aynı rolü üstlenmesinde sorunlar vardır. Bunun en önemli nedenini, işi sadece kullanıcının bilgi ihtiyacını karşılamak yani sorularının yanıtlaması olarak algılanmasında gören Chowdhury ve Chowdhury (2003), danışma hizmetinin temel işlevlerinden olan bireysel yardım ve kullanıcı eğitiminin elektronik hizmetlerde göz ardı edildiğini vurgulamaktadırlar. Iş̧in eğitim, öğretim, rehberlik ve bireysel yardım unsurlarının eksik kaldığını ve elektronik kütüphanelerin daha çok elektronik kaynaklar, bunların yönetimi ve erişimi üzerine odaklandıklarını ileri sürmektedirler. Pek çok kütüphanenin günün her saati kaynaklara uzaktan erişim sağlanabilmesini ve kullanıcıların sorularını kütüphaneye iletebilmesini yeterli görmesi, geleneksel danışma hizmeti anlayışının henüz elektronik ortama taşınamadığını göstermektedir. Oysa 
değişen bilgi ortamı, kullanıcıların bireysel yardım intiyacını daha da artırmaktadır. Ayrıca bugün kütüphanelerden bağımsız pek çok web tabanlı bilgi hizmeti internet üzerinden kullanıcılara sunulmaktadır. Danışma hizmetinin temel özelliği olan bireysel yardımla ilgili işlevlerin elektronik danışma hizmetlerinde uygulanması, kütüphaneler dışında oluşturulan bilgi hizmetleri ile arasındaki farkı ortaya koyması açısından da önemlidir.

Bugünün araştırmacıları doğru, güvenilir, ilgili ve kullanılabilir bilgiye çabuk ulaşmak istemektedirler. Bu intiyacın karşılanabilmesi için bilginin geleneksel olarak sağlama, tanımlama ve sunumundan; zaman ve mekana bağlı olmayan sanal ortamlarda işlenip erişimine geçiş sürecinde, danışma masasının bu değişime nasıl uyum sağlayacağı önemli bir sorudur. Kütüphanelerin 24 saat ve her gün hizmet verebilmeleri için işbirliğine giderek koleksiyon ve personel gücünü birleştirmelerinde yarar vardır (Kresh, 2000).

Tüm hizmet sektöründe olduğu gibi bu alandaki değişimlerin başarılmasında da en önemli unsur insan faktörüdür. Literatüre bakıldığında özellikle son on yılda danışma kütüphanecilerinin bu değişime bakış açılarının ve gelişmelere yaklaşımlarının incelendiği görülmektedir. Tenopir ve Ellis'in (1998) araştırmalarına göre değişimin kütüphaneciler üzerinde sürekli bir baskı oluşturmasına rağmen, kütüphanecilerin yeni teknoloji ve bilgi kaynaklarını kullanımları ile iş tatminlerinin artışı arasında bir ilişki vardır. Elektronik danışma hizmetinin yürütülmesinde kütüphanecilerin konuya yaklaşımı ve uygulamalar üzerine yapılan araştırmalar akademik ve halk kütüphanelerinde farklı uygulama ve yaklaşımlar olabileceğini ortaya koymaktadır. Genelde kütüphaneciler elektronik danışma hizmetinin gereğine, önemine ve çok daha erişilebilir olduğuna inanmakla birlikte bu hizmetin tüm sorunları çözemeyeceğini ve yeni yükler getireceğini de bilmektedirler (Janes, 2002).

\section{Sonuç}

Bugün olduğu gibi bundan sonra da danışma hizmetleri kullanıcı beklentilerinden ve değişen bilgi ve iletişim ortamlarından etkilenmeye devam edecektir. Bu etki, hizmetin veriliş biçimini, kullanıcı ile ilişkileri, koleksiyon seçimi ve değerlendirilmesi gibi bu hizmet çerçevesindeki pek çok işin kapsamını ve uygulama şeklini değiştirecektir. Ancak unutulmaması gereken hizmetin 
felsefesinin aynı kalacağıdır. Danışma hizmetinin amacı, bilgi arayan kişiye en kısa sürede en isabetli bilgiyi sunabilmek; kullanıcıya bilgiyi aramasında, erişmesinde, değerlendirmesinde, kullanmasında ve sunumunda gerekli olacak becerileri kazandırabilmektir. Bu hizmetin danışma masasında ve yüz yüze iletişimle sunulması, her iki tarafın birbirini tam olarak anlayabilmesine olanak vermesi açısından değerli ve önemlidir. Ancak gelişen araçlar ve değişen çalışma ortamları kullanıcıların uzaktan ve gereksinim duydukları an kütüphaneye başvurabilmelerine olanak tanımaktadır. Burada önemli olan bilgi ve iletişim alanındaki kolaylıkların yüz yüze iletişimin sağladığı avantajlarla nasıl birleştirilebileceğidir.

Elektronik danışma hizmetini geleneksel danışma hizmeti kapsamı içinde "bir iş, çağın gereği, diğer kütüphaneler yaptığı için bizim de yapmamız gereken bir uygulama" gibi görmek bu işe baştan yanlış başlamak anlamına gelebilir. Elektronik danışma hizmetine başlamadan önce bu uygulamaya neden gerek duyulduğu, kimlere nasıl verileceği, kullanıcıların beklentileri ve özellikleri, bu iş için ne tür donanım ve yazılımlara gerek duyulacağı, nitelikli bir hizmet için hangi ölçütlerin yerine getirilmesi gerektiği ve kütüphanenin bunu nasıl sağlayacağı, çalışacak personel sayısının ve özelliklerinin ne olacağı, işbirliği planları ve hizmetin nasıl değerlendirileceğinin önceden düşünülmesinde yarar vardır.

Ülkemizde de yeni yeni gelişmeye başlayan elektronik danışma hizmetlerinin nasıl algılanıp uygulandığı ve sorunları konusunda ayrıntılı araştırmalara intiyaç vardır. Pek çok kütüphane e-posta yoluyla kullanıcı sorularını yanıtlamaya başlamıştır. Bunun kullanıcı ve kütüphane açısından işleri kolaylaştıran bir uygulama olduğunu söylemek mümkündür. Sadece elektronik ortamda kullanıcıların sorularının yanıtlanması elektronik danışma hizmeti veriliyor anlamına gelir mi? Danışma hizmetinin elektronik ortama nasıl taşınacağı, en önemlisi temel görevlerinden biri olan kullanıcı eğitiminin web üzerinden nasıl verileceği danışma kütüphanecilerinin üzerinde tartıştığı konulardır. E-posta ile soruların yanıtlanması bu hizmet için bir başlangıç sayılabilir. Ancak bu yolla gelen soruların tamamının kütüphaneci için açık ve anlaşılır olduğunu söylemek mümkün müdür? Bu soruların etkileşimli olarak görüşülmesi ve kullanıcı isteklerinin kütüphaneci tarafından anlaşıldığının belirlenmesi önemlidir. Ayrıca bu soruların ne kadar sürede, kimler tarafından nasıl 
yanıtlandığının değerlendirilmesi hizmetin başarısı açısından gereklidir. Yurt dışında uygulamalarını gördüğümüz şekilde, ülkemizde de okul, akademik, araştırma ve benzer alanlarda çalışan kurum kütüphanelerinin bir ağ üzerinden ortak hizmet tasarlamaları, hizmetin hızını ve niteliğini artıracaktır. Bu yolla uzmanlaşmadan yararlanılabilir ve soru arşivleri geliştirilebilir. Bu da benzer soruların hızla yanıtlanması, araştırma sorularında deneyimli iş gücünden yararlanılması anlamına gelmektedir.

Danışma hizmetlerinin elektronik ortamda verilmesi kütüphane içinde sunulan hizmetlerin bütünüyle ortadan kalkacağı anlamını taşımaz. Nitekim bu hizmetleri birbirinin alternafi olarak değil, aynı amaç doğrultusunda birbirini tamamlayan uygulamalar olarak görmek gerekir. Kullanıcının bilgi ve eğitim intiyacının karşılanmasının esas olduğu unutulmamalı, bu nedenle yeni tarama teknikleri, veri tabanları ve uygulamaların her iki ortamda da kullanıcıya nasıl aktarılacağı üzerinde durulmalıdır. Ayrıca hizmetin kullanıcıya nasıl tanıtılacağı da önemlidir. Hizmetin kapsamı, işleyişi ve sınırları kullanıcıya ne kadar açık ve net anlatııırsa kullanım başarısı o denli artacaktır. lyi bir tanıtım danışma masasının yükünü azaltırken, kullanıcıların sorularını formüle etmelerine yardımcı olacaktır. Mesleki etik ve kullanıcı haklarına saygı ile ilgili kurallar, geleneksel ortamda olduğu gibi elektronik danışma ortamı için de geçerlidir. Ancak elektronik danışma hizmetlerini yürütürken elektronik ortamın özelliği gereği, kullanıcının özel yaşamına saygı ve gizlilik gibi değerlere daha çok dikkat edilmesi gerekmektedir.

\section{Kaynakça}

Bennett, B.A., Kasowitz, A. ve Lankes, R.D. (2000). Digital reference quality criteria. R.D. Lankes, J.W. Collins ve A.S. Kasowitz (ed. by). Digital reference service in the new millenium içinde (s. 65-80). New York: Neal-Schuman Publishers.

Chandler, Y.J. (2001). Reference in library and information science education. Library Trends, 50(2): 245-262.

Chowdhury, G.G. ve Chowdhury, S. (2003). Digital library services. Introduction to digital libraries içinde (s. 227-245). London: Facet Pub. 
Ellis, L. ve Francoeur, S. (2001). Applying information competency to digital reference. $67^{\text {th }}$ IFLA Council and General Conference (August 16-25 2001). Boston: IFLA.

Fritch, J.W. ve Mandernack, S.B. (2001). The emerging reference paradigm: A vision of reference services in a complex information environment. Library Trends, 50(2): 286-305.

Galvin, T.J. (1978). Reference service and libraries. Encyclopedia of Library and Information Science içinde (s. 210-226). New York: Marcel Dekker Pub.

Gorman, M. (2001). Values for human-to-human reference. Library Trends, 50(2): 168-182.

Janes, J. (2002). Digital reference: Reference librarians' experiences and attitudes. Journal of the American Society for Information Science and Technology, 53(7): 549-566.

Kresh, D.N. (2000). Offering high quality reference service on the web: The collaborative digital reference service (CDRS). D-Lib Magazine. [Çevrim içi], Elektronik adres: http://www.dlib.org/dlib/juneoo/kresh/06kresh.html [10 Temmuz 2003].

Lankes, R.D. (2000). The foundations of digital reference. R.D. Lankes, J.W. Collins ve A.S. Kasowitz (eds. by). Digital reference service in the new millenium içinde (s. 1-10). New York: Neal- Schuman Publishers.

Lipow, A.G. (2003). The virtual reference librarian's handbook. New York: Neal-Schuman Pub.

Lynch, P. (2000). Managing growth for Ask A services. R.D. Lankes, J.W. Collins ve A.S. Kasowitz (eds. by). Digital reference service in the new millenium içinde (s. 83-90). New York: Neal-Schuman Publishers.

Mardikian, J. ve Kesselman, M. (1995). Beyond the desk: Enhanced reference staffing for the electronic library. Reference Services Review, 23(1): 21-28. 
McGlamery, S. ve Coffman, S. (2000). Moving reference to the web. R.D. Lankes, J.W. Collins ve A.S. Kasowits (ed. by). Digital reference service in the new millenium içinde (s. 181-196). New York: Neal-Schuman Publishers, Inc.

Penka, J. (2003). The technological challenges of digital reference. D-Lib Magazine, 9(2):1-13. [Çevrim içi], Elektronik adres: http://www.dlib.org/ dlib/february/penka/02 penka.html [10 Temmuz 2003].

Sutton, S. (1996). Future service models and the convergence of functions: The reference librarian as technician, author and consultant. K. Low, (ed.). The roles of reference librarians: Today and tomorrow içinde (s. 131-138). New York: Haworth Press.

Tenopir, C. ve Ellis, L. (1998). The impact of digital reference on librarians and library users. Online, 22(6): 84-88.

Tyckoson, D. A. (2001). What is the best model of reference service. Library Trends, 50(2): 183-196.

Virtual Reference Desk. (2003). Virtual Reference Desk. [Çevrim içi], Elektronik adres: http://www.vrd.org/about.shtml [27 Haziran 2003].

Wilson, M.C. (2000). Evoluation or entropy: Changing reference/user culture and future of reference librarians. Reference and User Service Quarterly, 39(4): 387-390. 